\title{
EDUCAÇÃO NA INTERNET
}

\section{Mesmo os não muito familiarizados com a informática podem acessar a Rede Internet com facilidade}

O sonho de qualquer pesquisador sempre foi ter ao seu alcance todas as grandes bibliotecas do mundo. Como num conto de fadas, o pesquisador se via magicamente saltando dos fichários da Biblioteca de Coimbra aos de Salamanca; visitando coleções especiais em Frankfurt ou Oxford; dando uma conferida nos catálogos da Biblioteca do Congresso Americano; percorrendo os índices dos periódicos mais recentes incorporados à coleção da Sorbonne; lendo as resenhas bibliográficas dos últimos lançamentos em sua área de trabalho; compilando listas bibliográficas a partir de um acervo alojado em Oslo ou Chicago; pesquisando os abstracts de teses e dissertações defendidas na USP, em Tóquio, ou no Instituto de Tecnologia de Massachusetts.

Hoje tudo isso está se tornando realidade. A Internet possibilita incursões a bibliotecas reais, espalhadas pelos cinco continentes, sem que você deixe a sua mesa de trabalho, em seu gabinete na Universidade ou mesmo em sua casa. Em alguns casos é até mesmo possível fazer a "importação" de artigos, livros ou dissertações acadêmicas completas, com um simples comando nas teclas de seu computador. Você escolhe o que quer, digita seu endereço eletrônico ${ }^{1}$ e ZAAAAAAP, com a velocidade da luz o texto é transferido para o seu computador.
Aos poucos, os próprios acervos (e não apenas os catálogos) bibliográficos vão se tornando digitalizados e a maioria dos periódicos especializados, em todas as áreas científicas e artísticas, começam a ter também suas versões eletrônicas (on line), disponíveis através da Internet.

A atividade tipicamente gutemberguiana de consultar catálogos e compilar listas bibliográficas a partir dos acervos das bibliotecas continua sendo, evidentemente, parte fundamental de qualquer pesquisa acadêmica. No entanto, utilizar a Internet exclusivamente para isso seria tão absurdo quanto utilizá-la apenas para "namoros eletrônicos", como nas novelas da Globo, ou quanto comprar um telefone somente para saber a previsão do tempo ou a hora certa. Possibilitar acesso a catálogos e acervos de

\section{O AUTOR}

Marcos Palacios

É jornalista, Ph.D. em Sociologia pela University of Liverpool e docente do Programa de Pós-Graduação em Comunicação e Cultura Contemporâneas da Universidade Federal da Bahia (UFBa), E-mail: palacios@ufba.br.

1. Todos os usuários da Internet possuem um endereço eletrônico (e-mail). Trata-se de um nome, seguido de um símbolo conhecido como "arroba" (@) e a especificação do computador que "hospeda" aquele usuário. O e-mail do autor deste artigo, por exemplo, é palacios@ufba.br, o que significa que num computador da ufba (Universidade Federal da Bahia), no Brasil (br), existe um usuário codificado como palacios, que ali pode ser contatado. 
bibliotecas é apenas um dos muitos serviços que a Internet presta ao pesquisador.

Estamos entrando na era das Cyberbibliotecas. A rede telemática, conhecida como Internet, é hoje um imenso banco de dados que extrapola as paredes das bibliotecas convencionais, contendo, em contínua circulação e atualização, informações essenciais para o pesquisador de qualquer área científica ou artística, além de constituir-se num imenso fórum aberto e internacional para os mais variados tópicos de discussão e num espaço totalmente novo (e potencialmente poderosíssimo) para ativismos políticos de todos os tipos e colorações.

\section{COMO E POR ONDE COMEÇAR ?}

Para quem nunca acessou a Rede e tem pouca intimidade com computadores, tudo isso parece, no mínimo, assustador. $\mathrm{Na}$ verdade, basta perder o medo e dar os primeiros passos. Uma vez lá, o difícil vai ser você querer sair...

Nosso objetivo neste artigo é motivar os ainda temerosos ou recalcitrantes, indicando, em breves pinceladas, como se faz para ter acesso ao mais importante instrumento de pesquisa de nossos dias e procurando mostrar o que estará perdendo quem não se dispuser a dar o salto telemático.

Como a gama de recursos disponíveis para a pesquisa na Internet é muito ampla, previlegiaremos a World Wide Web
(WWW), a grande teia de informações disseminada pelo mundo, a Cyberbiblioteca do futuro, que já existe no presente. A WWW é apenas um dos instrumentos de pesquisa disponíveis na Internet, sendo complementada por recursos também muito poderosos como o Gopher, o FTP, as Listas de Discussão etc. Mas a WWW é, para muitos, o mais excitante de todos.

O que é a WWW ?

A WWW é uma grande teia de bancos de dados interligados, abrangendo máquinas das diversas redes que constituem a Internet.

Segundo Nicholas Negroponte, um dos fundadores do Laboratório de Multimeios do Instituto de Tecnologia de Massachusets, cerca de 45 mil redes estão hoje dentro da Internet, com mais de quatro milhões de computadores $^{2}$ e cerca de cinqüenta milhões de usuários espalhados por todo o mundo. Para visitar esses bancos de dados você necessita de um computador (ligado à Internet através de linha telefônica e um modem ${ }^{3}$ ) e de um programa (software) que permita a leitura de texto e a recuperação de material gráfico e sonoro (fotos, gravuras, cores, trilhas sonoras, efeitos de som etc.). Existem muitos programas para esse tipo de navegação na Internet, mas o Netscape e o Mosaic são os mais conhecidos e utilizados ${ }^{4}$.

2. Esses computadores interligados são os chamados "servidores". Trata-se, em geral, de grandes computadores (mainframes) aos quais estão acoplados muitos micros, que funcionam como terminais das máquinas maiores. Calcula-se que o número total de usuários na Internet aproxima-se dos 50 milhões, com projeções para um bilhão de usuários na virada do século. Uma interessante e divertida introdução ao mundo da telemática, seu estágio atual e seus efeitos presentes e futuros na vida social está em Vida Digital, de Nicholas Negroponte (São Paulo: Cia das Letras, 1995).

3. Um modem (o nome vem da expressão modulator-demodulator) é um aparelho que transforma bits em ondas e ondas em bits, permitindo a comunicação entre computadores. Na verdade hoje em dia o modem é apenas mais uma placa no interior de seu computador. As velocidades dos modens são medidas em bits por segundo, $9.600 \mathrm{bps}, 14.400 \mathrm{bps}$ etc. Um bit, em linguagem de Informática, é uma unidade mínima de informação.

4. Se você é um principiante, é mais prudente e, em última análise, mais econômico deixar em mãos de um especialista ou de um amigo "micreiro" a instalação e a configuração do programa de navegação em seu computador. Uma vez instalados, os programas são facílimos de usar. Se seu interesse for exclusivamente texto, nem é necessário usar qualquer programa especial, uma vez que o sistema UNIX, utilizado pelos computadores da Rede, incorpora um comando chamado Lynx, com o qual é possível acesso à WWW, sem recuperação de imagens. Basta digitar Lynx seguido do endereço do site na WWW. Você terá acesso aos textos, sem recuperação das imagens. 
Essa teia cresce continuamente e é acessível a qualquer usuário. Estima-se que cerca de mil novas máquinas são acrescentadas diariamente à Internet. As informações na WWW estão contidas em "páginas" (home pages) ou sites, isto é, arquivos em memórias de computadores, compostos por textos, sons e imagens. Como em cada computador pode haver mais de um site, é difícil calcular-se o número de "páginas" hoje existentes. Algo, talvez, em torno de $10 \mathrm{mi}-$ lhões, ou mais. E tenha-se em mente que "página" é um termo metafórico: uma "página" WWW pode conter centenas e até muitos milhares de páginas (no sentido estrito) de texto e imagens. A Enciclopédia Britânica, por exemplo, é uma "página" da WWW.

As "páginas" da WWW utilizam o hipertexto, uma modalidade de escrita (produzida numa linguagem chamada HTML $^{5}$ ) que interliga diversos documentos (localizados em diferentes arquivos). Através de palavras ressaltadas no texto (geralmente em negrito, itálico ou numa cor diferente), conhecidas como links (ligações), navegase de um arquivo a outro. Basta clicar um link (ou seja, selecioná-lo com o mouse ou com as setas de navegação e dar um enter) para passar de um documento a outro. E você pode acessar som e imagem com a mesma facilidade com que acessa texto ${ }^{6}$.

Quem trabalha com multimídia em seu computador conhece perfeitamente o processo. A diferença é que na WWW um clic pode levar de um computador a outro, de um continente a outro.
Cada "página" (ou site) tem um endereço próprio, chamado de URL ${ }^{7}$. Por exemplo, o endereço ${ }^{8}$ WWW (ou URL) do jornal Zero Hora de Porto Alegre é http://www.embratel.net.br/infoserv/zerohora; o da Universidade Federal da Bahia é http://www.ufba.br; a Enciclopédia Britânica está em http://www.eb.com.; a Biblioteca do Congresso Norte-Americano pode ser visitada em http://www.loc.gov. A Xuxa tem seu site em http://www.indirect.com/www/rcarter/xuxa, com fotos, biografia, programação de shows, letras de músicas etc. Milhões de "páginas" estão hoje disponíveis, abrangendo praticamente todos os setores do conhecimento humano. Cada uma delas tem seu endereço próprio e basta acessá-lo para lê-las na tela de seu computador, ou "importá-las", para posterior gravação em seu hard-disk ou num disquete.

Um problema na utilização da WWW é que não existe um Catálogo confiável de todas essas "páginas". Alguns guias, que costumam se intitular Páginas Amarelas da Internet ou da WWW, foram editados e estão à venda, mas como o crescimento da WWW é ininterrupto, eles se tornam obsoletos muito rapidamente. Os catálogos mais eficazes e úteis acabam sendo aqueles oferecidos on line na própria Rede, ou publicados periodicamente nas revistas especializadas. A revista Internet World, em sua versão brasileira, traz em cada edição mensal um suplemento atualizado de endereços WWW. Um Catálogo Brasileiro de WWW, listando as "páginas" nacionais no cyberespaço, está disponível em http://www.dcc.unicamp.br/ camcima/.

5. Iniciais de Hyper Text Markup Language.

6. Na verdade quase com a mesma facilidade. Devido a problemas de velocidade e qualidade das linhas telefônicas no Brasil e dependendo da velocidade de seu micro e do modem que você estiver utilizando, a recuperação de som e imagem pode ser um processo relativamente demorado e nem sempre muito bem sucedido. A tendência, no entanto, é a crescente facilidade de acesso.

7. Iniciais de Uniform Resource Locator. Existem várias siglas e muito jargão circulando na Internet, mas também existe um Dicionário de "Internetês" on line em http://www.public.iastate.edu/ pedro/pt_all/pt_dict.html, onde eu fui buscar o significado de URL ao escrever este artigo. O dicionário pode ser usado em qualquer das línguas da Comunidade Européia.

8. Os endereços URL são muitas vezes longos e complicados. É necessário digitá-los cuidadosamente para ter sucesso no acesso. Uma letra fora de lugar, ou a troca de uma maiúscula por minúscula (ou vice-versa) produz uma mensagem de erro. 
Felizmente para o pesquisador, existem pessoas e instituições que estão se dedicando a produzir sites especializados, que funcionam como índices para determinados assuntos. A partir desses sites é possível navegar diretamente, através de links, para uma série de outros documentos dentro de um mesmo assunto.

Não é necessário saber, por exemplo, o endereço de cada um dos jornais existentes na WWW para acessá-los. Existem sites que funcionam como verdadeiras Bancas de Jornais, de onde se pode acessar jornais de (quase) todas as partes do mundo.

Uma excelente Banca de Jornais holandesa, com links para publicações (jornais e revistas) de todos os continentes, arranjadas em ordem alfabética, está disponível em http://www.cs.vu.nl/ gerben/news.html.

Outra Banca excelente é o Newslink, localizada num computador nos Estados Unidos (http://www.newslink.com), oferecendo links para mais de 1000 jornais e revistas em todo o mundo.

Da mesma forma, seria extremamente incômodo se você tivesse que memorizar ou anotar os endereços de todas as bibliotecas que podem ser acessadas através da Internet. Vários sites WWW foram criados especialmente para servirem como porta de entrada não a uma, mas a dezenas ou mesmo centenas de bibliotecas, espalhadas por todo o mundo. Uma dessas portas, particularmente rica em conexões, está localizada em http://sjcpl.lib.in.us/homepage/PublicLibraries/PublicLibraryServices.html. Estar aí é, virtualmente, ter a seu alcance (quase) todas as bibliotecas do mundo. Os serviços oferecidos por cada uma delas variam, mas todas têm algo a dar ao pesquisador cybernauta. Aos poucos, oferecer mais e mais serviços ao usuário começa a ser também uma medida de prestígio dessas bibliotecas. E o pesquisador só tem a lucrar com isso.

\section{EDUCAÇÃO NA WWW}

Com mais de 10 milhões de sites na WWW, é evidente que não são apenas as bibliotecas conectadas que interessam ao pesquisador, por mais serviços que elas possam oferecer. Pode-se encontrar informações sobre praticamente tudo na WWW, de peixes de briga a abalos sísmicos na Lua, de educação a distância a receitas de peru recheado e sobremesas de chocolate 9 . O problema é saber buscar e saber selecionar. A questão não é de falta, mas de excesso de informação disponível.

Se o seu interesse é Educação então, certamente, o lugar mais indicado para iniciar suas explorações na WWW é a "página" de Educação da Rede Nacional de Pesquisa (RNP), em http://www.rnp.br/educ/educ.html. Organizada por assuntos (Educação de Adultos, Educação Superior, Educação a Distância etc., etc.), a "página" da RNP é uma excelente porta de entrada para o pesquisador que começa a se aventurar pela WWW. Lá você poderá encontrar bibliografias, artigos e livros sobre os mais variados temas, listas de eventos no Brasil e no mundo, descrição de projetos em andamento, informações sobre Educação a Distância e links para centenas de sites de interesse, mantidos por instituições educacionais no Brasil e no mundo. E tudo isso em português !!!

\footnotetext{
9. Receitas com chocolate (sobremesas, tortas, sorvetes, pizzas etc) estão em http://www.qrc.com/ sholubek/choco/start.html. Receitas italianas, de todos os tipos, podem ser encontradas na Mamma's Cuisine, http://www.eat.com. Uma lista geral de sites dedicados à culinária, por sinal alojada num computador da Nova Zelândia, está em http://www.vuw.ac.nz/non-local/recipes-archive/other-sites.html.
} 
Para facilitar o trabalho de pesquisa na WWW existem instrumentos chamados Search Engines, que fazem buscas automáticas, a partir de palavras-chave.

$\mathrm{O}$ pesquisador acessa $\mathrm{o}$ instrumento, indica que palavras deseja que sejam pesquisadas e recebe uma lista de sites da WWW que, possivelmente, seriam de interesse. Qual é seu campo específico? Educação Superior, Metodologia do Ensino, Sociologia da Educação, Educação Religiosa, Crianças Excepcionais, Pré-Escola, História da Educação? Indique sua área, e o Search Engine vai dizer a você para onde se dirigir, oferecendo conexões diretas e instantâneas, ao alcance de um simples toque numa tecla de seu computador. São vários os Search Engines disponíveis e, como eles buscam a partir de conjuntos de bancos de dados distintos, todos acabam se complementando.

Dentre os vários Search Engines existentes, o Lycos (http://lycos.cs.cmu.edu) é um dos que oferece a vantagem extra de produzir as listas de sites com pequenos resumos, que especificam seus conteúdos, permitindo que $o$ pesquisador decida se vale ou não a pena abrir aquele arquivo. Existem ainda o Webcrawler (http://www.webcrawler.com/WebCrawler/WebQuery.html), o Excite (http://www.excite.com), o Galaxy (http://galaxy.einet.net), o Altavista (http://www.altavista.digital.com), dentre muitos outros instrumentos de busca na WWW. Mas as opiniões variam sobre a eficácia de cada um e tudo acaba sendo uma questão de preferência pessoal.

Alguns sites agrupam e permitem acesso a vários Search Engines simultaneamente, como é o caso da "página" do campus da Universidade do Colorado (http://www.cs.colorado.edu), que oferece links com o Harvest System, WWW Worm e com a Biblioteca Virtual de Recursos WWW. Outro site desse tipo é o Global Village (http://www.globalcenter-- net/gcweb/tour.html), que inclui diversos recursos de busca e muita informação classificada por assuntos. Tente também o Web Search Engine and Indices, localizado em http://www.obscure.org/ jaws/websearch. $\mathrm{html}$ e o Internet Search Engines, um site inglês particularmente interessante em http://www.bbcnc.org.uk./babbage/iap.html, onde vários Search Engines estão agrupados.

Talvez o mais conhecido e popular dos sites de referência seja o Yahoo (http://www.yahoo.com), constantemente citado como um entre os dez mais quentes sites da WWW, em todos os tipos de enquetes. De fato, o Yahoo é um excelente instrumento de busca e um ponto de partida quase obrigatório para se localizar informações sobre assuntos disponíveis na WWW. Uma versão brasileira do Yahoo, batizada como YAHÍ, está sendo construída em http://www.ci.rnp.br/si/index.html, enquanto em http://www.iis.com.br/ gviberti/ você encontra o Cadê, um índice geral da Internet em português.

\section{LUGARES PARA VISITAR}

Apesar de que praticamente qualquer assunto possa ser encontrado no vastíssimo banco de dados em contínua construção e mutação que é a Internet, algumas áreas são mais bem servidas do que outras, em termos de material já acumulado e classificado, à espera de quem o utilize. Se o seu interesse de pesquisa for a Informática, em qualquer de suas manifestações (aplicações de computação a isto ou aquilo, redes, linguagens de computação etc.), você é um super-privilegiado em relação à quantidade de material disponível. Espantoso seria se assim não fosse, num meio de pesquisa constituído, basicamente, por computadores interligados....

A Educação, de um modo geral, é um dos campos mais privilegiados em termos de acúmulo de informação na WWW. E não só de informação. 
A Internet não oferece apenas recursos de pesquisa ao interessado em estudar a Educação, mas se constitui numa poderosa ferramenta de trabalho para se atuar em termos educacionais.

Através da Internet, programas de educação a distância, que já vinham sendo executados com a utilização de outros meios de comunicação ${ }^{10}$ (livros, jornais, rádio, TV etc.), atingem a idade da multimídia, uma vez que a Rede pode combinar as formas comunicacionais de todos e cada um dos meios que a precederam. Milhares e milhares de escolas de primeiro e segundo graus em todo o mundo (inclusive no Brasil) estão participando, neste momento, de programas educacionais em rede, através da Internet. Cursos são oferecidos, em salas de aulas virtuais, abrangendo uma enorme gama de assuntos $\mathrm{e}$ interesses. Discussões sobre os mais variados tópicos têm lugar através das Listas de Discussões que operam na Internet e são abertas a qualquer interessado ${ }^{11}$.

Você pode começar suas visitas pelas instituições brasileiras ligadas ao campo da Educação.

O Catálogo Brasileiro de WWW ( http://www.dcc.unicamp/ camcima/) lista mais de uma centena de sites sob a rubrica Educação, incluindo um grande número de Universidades brasileiras que oferecem diversos recursos e bancos de dados de interesse para o pesquisador.
Como já advertimos, o problema na Internet não é de escassez, mas de excesso de informação...

Um dos locais a ser visitado por qualquer pesquisador é certamente o link de Educação existente no Yahoo (http://www.yahoo.com). A área de Educação é particularmente bem servida no Yahoo. Lá você vai encontrar um índice que pode levá-lo a centenas de sites de interesse educacional.

Assim como o Yahoo outras "páginas" funcionam como verdadeiros trampolins para o pesquisador em Educação, que encontra ali portas (links) que permitem verdadeiras viagens pelo mundo dos bancos de dados especializados. Além da já mencionada "página" de Educação da RNP (http://www.rnp.br/educ/educ.html), o pesquisador tem à sua disposição uma enorme quantidade de sites especializados, localizados em computadores em todas as partes do mundo e acessíveis a qualquer interessado. Tente, por exemplo, visitar a Education Connection Page, localizada em http://www.eskimo.com/ user/zedu.html, a $E d u$ cation Resources (http://www.brynmawr.edu/faveplaces/sciedu.html), e a Education and Library Resources em http://www.state.wi.us/agencies/dpi/www/ed_lib.html. Todas elas são excelentes mega-índices de recursos disponíveis para o pesquisador em Educação.

É só uma questão de começar. O Tapete Mágico dos sonhos do pesquisador já é uma realidade...

10. Discutir o que é a Internet seria assunto para outro artigo. Talvez mais apropriado do que classificá-la como um meio de comunicação seja pensá-la como um ambiente comunicacional multimídia.

11. A Lista de Discussão EAD (Educação a Distância) é uma das mais importantes no Brasil no setor de Educação. Uma relação de listas de discussão e informações sobre como acessá-las pode ser encontrada on line na WWW em http://www.ci.rnp.br/ci/forms/busca-sist.html. 